\title{
Patrimonio y modernidad
}

\section{Henrique Urbano}

En los últimos años, el interés que despertaron los estudios sobre patrimonio dio lugar a que la noción fuera aplicada a realidades que otrora ella ignoraba. $Y$ ese hecho tiene una historia. No la voy a contar. Lo señalo empero porque algunos de los aspectos de los temas relacionados con el patrimonio no se comprenden sin esa referencia obligatoria a la evolución del vocablo. La Ilustración o las Luces es la línea demarcatoria. Fue a partir del siglo XVIII que el campo semántico relacionado con "patrimonio" sufrió profundas alteraciones. Coinciden esos cambios con lo que se podría llamar la ruptura epistemológica provocada por el advenimiento del pensamiento crítico. Me explico.

Entiéndase por ruptura epistemológica el reconocimiento de la brecha que se abrió entre lo que fueron las concepciones del universo $y$ formas de conocimiento anteriores a las Luces $y$ lo que, poco a poco, fue difundido y aceptado como reglas y método de la ciencia moderna. Simplificando, con algún abuso, las cosas, me atrevería a decir que el origen de esa inmensa herida abierta en el corazón del Occidente es la consecuencia de los blancos alcanzados por el pensamiento crítico, es decir la Tradición y la Religión. Sin esa dimensión crítica no se entiende lo que aún en nuestros días vamos viviendo y lo que, sin saberlo, hemos ido cambiando en nuestro paisaje mental y social. Será, pues, ese el pretexto para las líneas que escribiré.

Intentaré ilustrar mis disquisiciones con breves ejemplos. Algunos son conocidos aunque todavía puedan servir de tema para nuevas investigaciones. Al analizar la definición de "espacio público" me serviré del caso del indigenismo cuzqueño. Sin embargo, lo que más llama la atención es la poca importancia que se da a la "mirada turística" como expresión adecuada de la práctica social de las sociedades contemporáneas. A ese tema consagraré mis últimos apuntes. 


\section{I.- La idea de patrimonio en el contexto de la revolución cultural de la Ilustración}

\section{La noción de patrimonio}

La idea de patrimonio, por su mismo origen, apunta hacia el pasado. Patrimonio, es decir herencia recibida por vía paterna. Se afirma con él el recuerdo y con el recuerdo, la transmisión de una propiedad común tanto física como espiritual. La figura del padre, como función societal, determina la calidad de lo que se lega. Son rasgos masculinos en una sociedad obviamente estructurada en torno a la imagen paterna. "Patrimonio" es precisamente eso, es decir la proyección de la figura del padre dando existencia y nombre a lo que el tiempo ofrece a su prole'.

Ahora bien, a esa imagen tan venerable y tan antigua del padre en la sociedad occidental se enfrenta la revolución cultural de la llustración o de las Luces. La involucra en el rechazo a todo lo que huele a Tradición. $Y$ de paso también recuerda que las religiones que crearon el entorno cultural de Occidente se construyeron alrededor de la idea de padre, no diría en todas sus expresiones, pero por lo menos en muchas de ellas. $Y$ de eso quiero hablar en los próximos párrafos.

En la época del Renacimiento, se designaba con el vocablo "patrimonio" los objetos que se iban guardando a título personal en vista a crear un espacio de memoria del que se echaba mano en cualquier circunstancia. Los reyes y los aristócratas-mecenas seleccionaban piezas antiguas, obras de arte $u$ objetos de la más variada procedencia, a fin de dar a su

\footnotetext{
'Sobre los orígenes de la palabra "patrimonio", véase André Desvallées, "A l'origene du mot patrimone", Dominique Poulot, ed., Patrimoine et modernité (Chemins de la mémoire), L'Harmattan, Paris, 1998:89-106.También Jean-Yves Andrieux, Patrimoine et histoire, Belin,Paris, 1997: 9-26. Para una idea de la polisemia de la palabra "patrimonio", véanse los textos del seminario dirigido por Henri Pierre Jeudy, ed., Patrimoines en folie, Editions de la Maison des sciences de l'homme,Paris, 1990. Los textos de otro debate de interés excepcional están publicados en Daniel J. Grange et Dominique Poulot, L'esprit des lieux. Le patrimoine et la cité, PUG, Grenoble, 1997.
}

entorno social y cultural el peso de la memoria familiar, y de señalar la importancia de la herencia propia. El papado fue uno de los más notables promotores de esa conciencia valorativa del pasado, y del uso y destino que los objetos cotidianos o artísticos que lo representaban deberían tener para definir los valores que presidían la marcha de la sociedad. Conocidas también son las preocupaciones que algunos príncipes italianos tenían por la formación de colecciones y bibliotecas donde las obras de la Antigüedad ocupaban un lugar prominente. Al construir. El Escorial, Felipe II introdujo en sus muros muchas de esas obras de colección y entre sus más notables iniciativas, se cuentan la formación de la biblioteca y sus importantes colecciones de pintura ${ }^{2}$.

La llustración no borró la idea de patrimonio 3 . Sus preocupaciones oteaban otros horizontes. Pero al erigir en principio universal la crítica de la Tradición y Religión, sospechó que por detrás de la herencia patrimonial se escondían los símbolos que identificaban a una y a otra. De ahí la reivindicación de un ejercicio de la crítica sobre los objetos patrimoniales. Se apropió de ellos y donde pudo los convirtió en símbolos de la Razón y del Progreso. Y a los que no pudo reutilizar los abandonó a la incontrolable sed de saqueo y destrucción. También ellas eran parte de la ola que barría con todo lo que no se sometía a los imperativos revolucionarios. De las cenizas recogió la llustración la idea de que el patrimonio era parte de la herencia pública y que cabía al Estado administrarlo. Desde ese entonces, nunca más la palabra "patrimonio" abandonó el discurso del Estado. Y como lo señalaré más adelante, sirvió para producir la propia conciencia de la Nación 4 .

No obstante, sea cual sea el ángulo de ataque, la idea de patrimonio no cortó sus vínculos con el pasado. No puede deshacerse de él,

\footnotetext{
${ }^{2}$ Manuel Fernández Alvarez, Felipe II y su tiempo, Espasa, Madrid, 1998: 893916.

${ }^{3}$ A propósito de ese tema, léanse las páginas de la seccióu tercera del libro de Daniel J. Grange et Dominique Poulot, op. cit., Paris, 1997: 331-426; Rainer Rochlitz, L'art au banc d'essai, Gallimard, Paris, 1998.

${ }^{4}$ Luc Ferry et Alain Renaut, Philosophie politique, 3: Des droits de l'homme à l'idée républicaine, PUF, Paris, 1996.
} 
porque es constitutivo del campo semántico que él mismo define. Por eso, la idea de herencia le es connatural. Acorralada empero por el discurso crítico del siglo XVIII, busca identificarse con los ideales perseguidos por las clases que, asidas a los gestos revolucionarios, mayormente a los de la Revolución francesa, redefinen el lenguaje público y le asignan un destino colectivo. Según ellos, el patrimonio es la herencia de la Nación. Y también es parte de la "memoria colectiva" a que recurrirá el pensamiento sociológico francés para designar lo que los grupos o clases retienen en el transcurso del tiempo. Cierto, ni "herencia" ni "memoria colectiva" nos alejan del campo del pasado, y la primera más que la segunda. De igual modo, gira en torno a ella otra noción: la de identidad, a la que me referiré más adelante. Me detengo en la noción de "memoria colectiva".

\section{Herencia, memoria colectiva y conciencia colectiva}

"Memoria colectiva" es una expresión sencilla y clara. Sin embargo, desde el momento en que le exigimos rigor pierde algunas de sus alhajas. Las cosas se complican más cuando se trata de ahondar en el adjetivo que acompaña "memoria", es decir "colectiva". Hablando con propiedad, la memoria se fragmenta desde el momento en que busca fijar su atención en algún objeto particular. Le prestan su dimensión colectiva los grupos o clases sociales. $Y$ en ese sentido, se puede afirmar que, por ejemplo, una familia conserva su memoria. Las instituciones tienen la suya. Cada de uno de esos cuerpos va guardando los hechos más significativos y las palabras más nobles que sus miembros prefirieron. Quedan registradas como si fueran una herencia común. Se pueden, pues, definir como patrimonio del grupo o de la institución 5 .

\footnotetext{
5Convendría debatir la noción de "herencia" porque como la de "patrimonio" designa hoy día un conjunto de realidades muy distintas entre ellas. A título de ejemplo,véase John Urry, Consuming Places, Routledge, London, 1997.

6Maurice Halbwachs, Les cadres sociaux de la mémoire, PUF, 1952 (1a. ed., 1925); del mismo autor, La topographie légendaire des Evangiles en Terre sainte, pref. de Fernand Dumont, PUF, 1971 (1a. ed., 1941).
}

Uno de los autores clásicos en la materia es el sociólogo francés Maurice Halbwachs ${ }^{6}$. Se adentra en el tema a través de medios tan sencillos como hábitos y gestos cotidianos, recuerdos y objetos anodinos. Con ellos construye Halbwachs lo que se podría llamar el discurso del patrimonio familiar, que no es distinto de la conciencia que habita todo el grupo. Ejemplos de ello son los grandes linajes reales, donde la memoria se confunde con el poder político. En los Andes, recuérdese la palabra que el discurso mítico guardó. Con ella los grupos cuzqueños de poder comparten la misma figura del inca para crear una herencia común y construir un espacio político tan ancho como el que en nuestros días diseña gran parte de los países andinos. Esa es una de sus propiedades: el patrimonio creado por la memoria y la palabra que lo expresa produce en el grupo el sentimiento de compartir una misma herencia y de atar los lazos que la hacen posible? . En ese sentido, herencia, memoria y patrimonio son expresiones de un mismo espacio mental y social.

Hay algo más en lo que fue una de las más brillantes expresiones de la construcción del objeto sociológico en Francia desde finales del siglo XIX hasta la década de los años cincuenta de este siglo. Me refiero a la invención de la idea misma de Sociedad de la que Durkheim es padre ${ }^{8}$. No sólo marcó profundamente el pensamiento francés, sino también le dejó hasta nuestros días obsesionado por la idea de que son las expresiones mentales las que dan cuerpo a las formas sociales $y$, por ende, a la sociedad misma. $Y$ por más extraño que parezca, cabe en ese campo la idea de patrimonio porque sin ese vínculo umbilical con la memoria colectiva ni la idea de herencia existiría ni la conciencia de pertenecer a un grupo se desarrollaría. Me explico.

\footnotetext{
${ }^{7}$ Henrique Urbano, Wiracocha y Ayar. Hëroes y funciones en las sociedades andinas, CBC, Cuzco, 1981; Henrique Urbano, comp. Mito y simbolismo en los Andes. La palabra y la figura (Estudios y debates regionales andinos, 84), CBC, Cuzco, 1993

${ }^{8}$ Aunque Emile Durkheim haya escrito numerosas páginas sobre el tema, su obra Les formes élémentaires de la vie religieuse, publicada en 1912, es el máximo exponente de su pensamiento sobre la materia |Existe tr. cast.: Las formas elementales de la vida religiosa, Akal, Madrid, 1982].
} 
Si algo hay de característico en la producción de la idea de Sociedad al comienzo del siglo $X X$ es precisamente la toma de conciencia de que la sociedad existe como sociedad y no como un producto de la voluntad de los dioses. Durkheim lo afirmó hasta la obsesión: la sociedad es lo que auna los individuos y los transforma en grupo. No es la suma de los individuos. Es algo así como una fuerza invisible que empuja a cada individuo hacia un objetivo común y que los une en un ideal compartido y colectivamente vivido. Para demostrar su intuición recurrió a las sociedades que él consideraba más simples, apoyado en estudios antropológicos, sobre todo ingleses. $Y$ se acogió a la idea de que esas sociedades con organizaciones sociales simples habian imaginado y nombrado esa fuerza invisible a través de sus dioses y expresiones rituales. El sagrado era, pues, el campo de ejercicio de la propia Sociedad donde ella organizaba su propio culto y difundía sobre los grupos o clases su energía colectiva.

Con esa novedosa concepción, Durkheim transformaba las antiguas concepciones del mundo y de las cosas, en expresiones del esfuerzo de los hombres por apropiarse de la conciencia de la existencia de la Sociedad. En otras palabras, las sociedades antiguas proyectaron en dioses y religiones lo que era la esencia misma de la vida social. Ahora bien, la llustración y el pensamiento crítico permitieron que finalmente se pudiera reivindicar para la Sociedad lo que a ella pertenecía. Y el discurso sociológico creaba su propia ideología con el pretexto de asumir el papel que la Tradición y la Religión desempeñaron en la producción de una imagen del grupo y de la fuerza colectiva que lo animaba.

\footnotetext{
${ }^{9} \mathrm{La}$ obra donde Bourdieu expresa mejor ese punto de vista es en Pierre Bourdieu, La distinction, Paris, Minuit, 1979. También Pierre Bourdieu, Le sens pratique, Minuit, Paris, 1980. Esta última obra es frecuentemente citada en la literatura antropológica americana, pero en la traducción inglesa de la primera versión francesa de Bourdieu. Esquisse d'une théoric de la pratique, Droz, Genève, 1972. Conviene referirse a Le sens pratique porque expresa el pensamiento revisado por el propio autor. Para un análisis crítico de la obra de Bourdieu, véase Léctures de Pierre Bourdieu, Cahiers du LASA, n. spécial 8 9, Université de Caen, 1988.
}

\section{La idea de habitus en la herencia patrimonial}

Más recientemente y bebiendo en la misma tradición, Bourdieu recordó que los grupos o clases sociales obedecían a ciertos principios que tenían por origen la conciencia de compartir una herencia común hecha de gestos, palabras, saberes y gustos ${ }^{9}$. $Y$ se reproducian guardando las mismas características e intentando conservar lo que cada una de ellas poseía de más significativo para el grupo. $Y$ hurgando en la filosofía antigua y medieval eligió la palabra habitus. A ella me referiré.

Mirándola de cerca y examinándola, no cabe duda que cuadra bien con la idea misma de patrimonio. Habitus es, para Bourdieu, lo que constituye el patrimonio de un grupo o clase y le da cuerpo y hasta razón de ser. Es decir, la herencia y su reprodución simbólica dentro de los límites de los grupos o clases sociales garantiza la pervivencia de los elementos constitutivos de la comunidad o sociedad diferenciada por patrimonios jerarquizados. Habitus son los gestos y palabras específicos de un grupo o clase, es decir aquello que los transforma en hecho visible. El habitus es la marca de origen y el patrimonio su contenido simbólico.

Resumiendo los anteriores propósitos, el pensamiento crítico ha abierto el camino para que sea posible recuperar para la propia sociedad la idea que los grupos o clases se hacen de sí mismos. Para que se entienda la revolución que esa operación produjo hay que tener en cuenta que la Tradición y la Religión eran los depositarios de la representación social, es decir de todo aquello que expresaba simbólicamente la vida comunitaria. La Religión lo había sacralizado y la Tradición asentaba en Ella su autoridad indiscutible. Las dos eran los depositarios privilegiados de la imagen de la propia sociedad y de todo lo que ella representaba para la vida colectiva. En ellas se concentraban las dimensiones semánticas de la idea de patrimonio porque la sociedad, proyectada en dioses, seres o héroes divinizados, guardaba intangible la 
Palabra original que fundaba las sociedades y las constituía en seres con espacio propio y herencia común. Bourdieu lo reivindica para los grupos o clases. El habitus es el patrimonio de un grupo o clase, la expresión de sus ideales, de sus normas y valores, de sus gestos y palabras.

\section{II.- Patrimonio y la invención del espacio público}

\section{La invención del espacio público}

Lo que también permitió y facilitó la toma de conciencia de la sociedad como construcción histórica y luego su aislamiento del universo mítico y religioso de las concepciones antiguas del origen del mundo y de las cosas fue la producción paulatina de un espacio público ${ }^{10}$. Al mismo tiempo que éste emergía y se diseñaban sus contornos se daban las condiciones para diferenciar lo que en la sociedad era común al conjunto de los grupos y clases sociales y lo que los distinguía entre ellos. Simultáneamente se agrietaba la vieja idea de la sociedad basada en los dictámenes de la Revelación divina o en la idea filosófica de Naturaleza humana. Era ésta el fundamento de una concepción ahistórica de la sociedad, a cuyo imperio se sometían los hombres en la búsqueda de la vida común perfecta $e$ inmutable. Según ese principio, reencontrarse con la Naturaleza era cumplir con las normas del designio divino inscritas en el gesto de un acto creador $^{11}$. Ahora bien, al señalar la posibilidad de producción de la sociedad no como un don de los dioses ni como una ley implacable de la Naturaleza, la revolución cultural provocada por la conciencia crítica de la llustración abría las puertas al juego libre de los individuos en la

\footnotetext{
${ }^{10}$ Como para los otros temas de la modernidad, el gran autor contemporáneo y autoridad en la materia es Jürgen Habermas, Struktumvandel der Offentlichkeit, Suhrkamp Verlag, 1990. Para una discusión sobre la posición de Habermas, "Les espaces publics", Cuaderni, La revue de la communication, 18 (automne 1992): 61-191. Para América Latina véanse los textos reunidos en François-Xavier Guerra y Annick Lempérière, comp., Los espacios públicos en Iberoamérica. Ambigüedades y problemas. Siglos XVIII-XIX, FCE, México, 1998.

11 Jean -Claude Lefeuvre, "De la protection de la nature à la gestion du patrimoine naturel", Henri Pierre Jeudy, ed., op. cit., Paris, 1990:29-76.
}

producción de la sociedad misma. Así lo entendieron, primeramente las clases burguesas del siglo XIX y luego todos aquellos que afirman el principio supremo de la experiencia democrática sobre cualquier otro principio de construcción de la sociedad moderna. Insistiré sobre este punto sin perder de vista el argumento que desarrollaré luego sobre espacio público y patrimonio.

Al emerger de las ruinas del orden social antiguo y de las cenizas abandonadas de la ola de reivindicaciones sociales que caracterizaron el nacimiento de la experiencia de la modernidad en el siglo XVIII, el espacio público definía todas aquellas prácticas sociales que permitían la toma de conciencia de la historicidad de la sociedad a la que aludí líneas más arriba. Es decir, al crear esos espacios se producían simultáneamente las condiciones de intervención en la propia sociedad, no como en algo a lo que había que someterse y obedecer (idea de Naturaleza humana), sino como partícipe en una empresa en que actuaban grupos y clases con objetivos propios y dferenciados. Hablar de espacio público es, pues, asumir el papel de definidor de la sociedad y, consiguientemente, de productor de una institución. Sin el siglo XVIII y la llustración, $\sin$ las reivindicaciones sociales que se apropiaron de los espacios que el Antiguo Régimen les negaba, no se hubiera dado la ruptura epistemológica a que he hecho referencia.

Consiste, pues, el espacio público en la construcción de una sociedad fundada en la definición de la práctica de grupos y clases persiguiendo objetivos contrastados. $Y$ no fue tan fácil como a primera vista se cree tomar conciencia de ello. Siguiendo el hilo de la crítica de las Luces, Durkheim trataba de aislar la idea de Sociedad y prestarle todas las características de una concepción racional del mundo y de las cosas. No obstante los rigores lógicos que empleaba, cedió a la tentación de elevarla a las cumbres de expresión, diría yo, sacra de la realidad, en la medida en que ella era objeto de un ritual colectivo y de adoración inconsciente de los grupos en sus funciones de partícipes y de 
constructores colectivos de una vida en común. Ahora bien, el pensamiento crítico y las condiciones que permitían su existencia, es decir el espacio público, corrían por senderos opuestos y reivindicaban la idea de sociedad para la propia sociedad, producto de la práctica misma.

\section{Espacio público y la invención patrimonial}

Quizá se comprenda ahora mejor adónde apuntan las anteriores reflexiones. Pretenden demostrar cómo a partir de la creación de espacios públicos se crean también las condiciones que hacen posible la invención patrimonial en el contexto de la visión crítica de la modernidad. Al alejar del horizonte mental la Religión y la Tradición, pilares de las sociedades antiguas, la llustración obligaba a la propia sociedad a dar lugar a las clases emergentes y a rediseñar la memoria en función de la participación activa de los grupos en la construcción de la vida colectiva. Porque una cosa era referirse a objetos 0 , de modo más general, a gestos y palabras heredadas y seleccionadas por una voluntad aristocrática que reivindicaba derechos de propiedad sobre el conjunto de la sociedad en cuanto depositaria de un designio divino de organización social, y otra cosa, producir un discurso partiendo de prácticas sociales compartidas por grupos $y$ clases persiguiendo objetivos distintos, y en no pocos casos, contrarios. Desde ese entonces, es decir con el advenimiento del siglo XVIII, la producción de espacios creó las condiciones para la eclosión de una conciencia patrimonial asida a la práctica social que caracterizaba cada grupo o clase. Más aún: el patrimonio, en vez de definir la inmutabilidad de la Naturaleza y la belleza del orden providencial establecido por voluntad divina, pasa a ser el recurso histórico de los grupos y clases que se apropian del espacio público y que buscan razones y la coherencia del discurso para existir en cuanto grupos o clases diferenciadas.

Se comprendrá también mejor que al otorgar a la sociedad la propiedad de ser un producto de la práctica de los grupos y clases, el patrimonio se diferencia por la práctica misma, es decir por el aporte que cada grupo o clase hace a la construcción de la propia sociedad. Para dar más claridad al argumento, pongo por caso la práctica social de los grupos feministas que son más contemporáneos y más visibles que las experiencias de la clase obrera del siglo XIX. $\mathrm{Al}$ invadir el espacio público luego de reivindicar para ellos un lugar propio, la práctica social desarrollada por esos movimientos hurga en la herencia olvidada o en el patrimonio subyugado y velado de la sociedad lo que le corresponde como partícipes en la construcción de la vida colectiva. La operación es patente: crear el espacio público, entrar en el juego de prácticas sociales, es, al mismo tiempo, echar los fundamentos de una conciencia patrimonial. Me atrevería a decir que el esfuerzo para acceder al patrimonio propio es el gesto imprescindible de la coherencia del lenguaje que presidirá la lógica de la construcción del propio grupo o clase.

\section{III.- Modernidad y construcción del objeto patrimonial}

\section{Ilustración y modernidad en el Perú}

Entre las paradojas que vivió la sociedad peruana y que le dejó algunas marcas en la piel, la de su difícil y contradictorio acceso a las grandes ideas del pensamiento ilustrado es una de ellas ${ }^{12}$. No fue una experiencia en carne propia. Como muchas ideas que llegaron al Perú, las de "igualdad, fraternidad y libertad", lema

\footnotetext{
${ }_{12}$ Para todas estas cuestiones ver Henrique Urbano,comp., Modernidad en los Andes (Debates andinos, 17), СBC, Cuzco, 1991; Henrique Urbano, comp., Tradición y modernidad en los Andes (Estudios y debates andinos, 86), СBC, Cuzco, 1992.

13Mona Ozouf, "Liberté, Egalité, Fraternité", Les lieux de mémoire-3, dir. Pierre Nora, Quarto, Gallimard, 1997. No dejará de llamar la atención un hecho asaz insólito en los símbolos políticos peruanos: la música de $\mathrm{La}$ Marsellesa adoptada por el partido del APRA.

${ }^{14}$ Scarlett O'Phelan, Un siglo de rebeliones. Perú y Bolivia 1700 1783,CBC,Cuzco,1988; de la misma autora, La gran rebelión en los Andes:De tupac Amaru a Tupac Catari,CBC, Cuzco, 1995; VV.AA., Actas del coloquio internacional "Túpac Amaru y su tiempo", Lima y Cuzco,1980; Luis Durand Florez, La revolución de los Tupac Amaru. Antología. Comisión NAcional del Bicentenario de la Rebelión Emancipadora de Tupac Amaru, Lima, 1981; Nicholas A. Robins, El mesianismo y la semiótica indígena en el Alto perú. La Gran Rebelión de 1780-1781, Hisbol,La Paz, 1998.
} 
inconfundible de la Revolución francesa, entraron aisladas, con la curiosidad del viajero y la lucidez solitaria de algun dirigente político ${ }^{13}$. La mal llamada Ilustración española, confundida con la renovación administrativa y el esfuerzo por modernizar el aparato eclesiástico, no era la mejor arma para apoyar una entrada en el país de los filósofos y pensadores de la revolución cultural que vivían en desasosiego en Europa en tiempos de las Luces. En el Virreinato del Perú, barrían los vientos otros páramos ideológicos y las reformas borbónicas tapaban momentáneamente algunas de las contradicciones que cimentaban la sociedad virreinal. A fines del siglo XVIII, la rebelión de Túpac Amaru II atrae la mirada de los observadores no para discutir razones filosóficas acerca del destino del hombre y de la sociedad, sino para garantizar la pervivencia de la legitimidad del poder español en los Andes ${ }^{14}$. Vendrá luego el proyecto político de la Independencia americana, pensado y amasado fuera de nuestras fronteras y con razones ajenas en su expresión ideológica. La inteligencia de Simón Bolivar estaba empapada de ideas ilustradas. Era la excepción. El pensamiento crítico no cuajaba en tierras andinas y la indiferencia o la ignorancia lo expulsaban de nuestros claustros y teatros literarios. Las consecuencias son varias. Mencionaré con algún desorden algunas.

Barrunto que la pervivencia de prácticas a las que los revolucionarios europeos de los siglos XVIII y XIX Ilamaban "oscurantistas" tiene algo que ver con la ausencia del pensamiento ilustrado y crítico en tierras andinas. Creerán algunos que lo que se señala es una simple referencia a modas pasajeras. Se equivocan. Es un problema de fondo y de consecuencias insospechadas. Por lo que escribi más arriba se debe entender esa laguna, primeramente como la

\footnotetext{
${ }^{15}$ Aunque existan "historias" de la Iglesia católica peruana no se ha estudiado con la atención que el asunto merece el papel de la Iglesia a fines del siglo XIX, comienzos del siglo XX. A mi modo de ver, sería importante profundizar algunos de los temas relacionados con el movimiento católico promocionado por Ios papados de León XIII y Pio X.

16 Casi siempre se hace referencia a la obra de Manuel González Prada. Es un buen ejemplo de lo que se podría llamar el pensamiento crítico con una innuencia francesa muy pronunciada. Su crítica a la Iglesia y a la Tradición lo ubica en un contexto ideológico muy cercano a los ideólogos de la Revolución francesa. Léanse, por ejemplo, las crónicas de Páginas libres, Paris, 1894; Lambién Manuel González Prada, Obras, Copé, Lima, 1988.
}

ausencia de espacios públicos; en segundo lugar, como la permanencia de formas discursivas y de sus respectivas prácticas sociales claramente dependientes de expresiones de lenguaje político obsoletas. La influencia del pensamiento católico más tradicional tiene algo que ver con ello. Y la presencia, o mejor dicho la omnipresencia de la Iglesia no permitía ni siquiera pensar que la crítica ilustrada pudiera sentar reales en un siglo $X I X$ tormentoso, y sobre todo trágico en muchos de sus lances ${ }^{15}$.

La ausencia de espacios públicos en el alba de la Independencia manifiesta una evidente falta de grupos que los reclamen. El uno va con el otro. Me recordarán algunos que se escucharon voces aisladas, algunas de ellas agudas $^{16}$. Sin embargo, una golondrina no garantiza la llegada de la primavera. Las voces solitarias no crearon corrientes capaces de hilvanar las voluntades. López Aldana fue una de ellas ${ }^{17}$. Venía de Colombia y sentó reales en Lima antes de buscar refugio en Buenos Aires, donde editó material panfletario sobre el destino del Virreinato peruano. A él debemos el Diario secreto de Lima ${ }^{18}$.

Sin querer tomarlo como la primera expresión de intento de creación de un espacio público, me referiré a un hecho que hoy día conocemos mejor: la producción de indigenismos peruanos. Zahondaré este tema.

\section{Un espacio público peruano: el discurso indigenista 19}

\footnotetext{
17Joëlle Chassin, "Lima, sus élites y la opinión durante los últimos tiempos de la Colonia", François-Xavier Guerra y Annick Lampérière et al., op.cit. México, 1998: 241-269.

18 lividem.

${ }^{19}$ En los últimos veinte años, la literatura indigenista llamó la atención de gran número de investigadores tanto nacionales como extranjeros: Efraín Kristal, Una visión urbana de los Andes. Génesis y desarmollo del indigenismo en el Perí: 1848-1930, IAA, Lima, 1991. Se publicaron también algunas de las investigaciones, donde no faltan excelentes páginas de historia de las ideas: Mirko Lauer, Andes imaginarios. Discurso del indigenismo-2, SUR/CBC, Lima-Cuzco, 1997. Como testimonio de esa época y práctica social, mencionaré el texto de José Matos Mar, José Deustua C., José Luis Rénique, eds., Luis E. Valcárcel, Memorias, IEP, Lima, 1981. Menos conocido, pero no menos intercsante es el movimiento que tuvo como actores Dora Mayer y Pedro S. Zulen: Wilfredo Kapsoli, El pensamiento de la Asociación Proindigena (Debates rurales, 3), CBC, Cuzco, 1980.
} 
De la discusión que Valcárcel animó desde el Cuzco, en la primera mitad del siglo XX, resultó lo que se podría llamar la ampliación del espacio público peruano con la inclusión del indio en el discurso societal. Sin saberlo, es él quien permite al intelectual mestizo cuzqueño racionalizar la sociedad peruana, en la medida en que el indio siendo el "otro", separa los grupos, jerarquiza los estamentos, diferencia las clases. El indio era la categoría mental que permitía al mestizo "pensar" la sociedad. En cuanto ser excluido de la sociedad republicana, el indio era paria en su propio mundo como también lo eran las mujeres, los chinos y las incipientes formas de grupos obreros. Vivía aislado y sometido a lo que Valcárcel denunció como gamonalismo serrano cuzqueño.

El lenguaje despiadado de Valcárcel no debe ser comprendido sólo por la voluntad indomable de abrir al indio serrano, postrado en la miseria, un camino que le había sido cerrado por la propia sociedad gamonal andina. Se entiende mejor la pasión de la lucha si se tiene en cuenta que el propio gamonalismo impedía a los emergentes intelectuales cuzqueños exhibir sus propias alhajas, es decir aquello que en su imaginación guardaba las antiguas glorias andinas prehispánicas. Al mantenerlos bajo las formas más sórdidas de trabajo y dominación, la sociedad serrana cuzqueña encerraba en su propia postración lo que quedaba de señal y memoria vivida de la antigua cultura andina. El gamonalismo no era sólo una forma arcaica de explotación y organización del trabajo con resabios esclavistas, sino también la cárcel que impedía la eclosión de un discurso andino estructurado en torno a la cultura prehispánica, mayormente incaica. De ahí la vehemencia de la denuncia del paladín del indio.

Sabido es que los años 1920 y 1930 se dividieron en discursos contrastados y competitivos. Sin alinear sus puntos de vista con los del presidente Leguía (1919-1930), Valcárcel

\footnotetext{
20Valcárcel explica en sus memorias las razones por las que se opuso a Leguía y las relaciones con el movimiento de Sánchez Cerro: Luis E. Valcárcel, $o p$. cit., Lima, 1981: 222-233; para la historia general del período, Enrique Chirinos Soto, Historia de la República, 1883-1968, t. II, A. Ch. Editores, Lima, 1991: 113-207.
}

encajaba bien en la ola reivindicativa de los derechos de la región 20 . Sus éxitos fueron relativos. Sin embargo, lo que no pudieron alcanzar los intelectuales cuzqueños en su expresión arcaica y tradicional de corte indigenista lo lograron, en forma oblicua y desviada, las formas del incipiente capitalismo que se acercaba a la sierra surandina con donaires de gran dama. La señal más clara la dio la construcción de la vía férrea que rasgaba las rocas andinas y transformaba en realidad cotidiana el sueño milenario de acceso a la ceja de montaña y a la selva amazónica. De paso, la sierra sur escapaba a las pretensiones costeñas, no totalmente, es cierto, pero parcialmente en la medida en que el flujo de la mercancía retomaba la dirección de la vieja ruta de los arrieros virreinales, la del sur hasta la costa atlántica con paso obligatorio por Buenos Aires. Estamos en 1923.

El advenimiento del mercado y del consecuente modo de producción capitalista cambia radicalmente el paisaje socioeconómico serrano andino cuyas estructuras socioeconómicas, en ese entonces, eran ya decadentes. Hablo de la hacienda como núcleo alrededor del cual se había organizado la producción y el trabajo. En ella el indio era un peón anónimo que prestaba al señor lo que le restaba de energía. Ahora bien, donde el mercado actuaba como posible puerta de entrada para la sociedad civil y para que entre el viento de la libertad que el discurso igualitario anunciaba desde el alba de la modernidad, la postración y miseria del indio servían de espejismo en la producción del discurso indigenista. Ojo: el indio no era el productor de su propia práctica social sino el pasivo espectador de un universo que le era totalmente ajeno.

\section{Valcárcel y la construcción patrimonial}

Valcárcel y los escritores indigenistas cuzqueños de los 1920 y 1930 consiguieron que algunas de sus propuestas fueran gratificadas con la realización de políticas locales y más tarde con ecos nacionales. Leguía fue desplazado por 
Sánchez Cerro. El anticriollismo limeño del dictador (1930-1933) era notorio. ¿Qué papel desempeñaron Valcárcel y sus más allejados? El hecho tiene su importancia. Importa subrayarlo21.

Hay que distinguir dos niveles: el universo de la representación y el universo de la práctica. Aquél asume que el indio es una categoría discursiva. Mientras éste lo hace presa fácil de un modo de producción agrietado y arcaico, del segundo da cuenta el remedo de producción capitalista a que me referí líneas arriba. Los indigenistas se ocupan del primero y con la figura del indio adquieren su propia legitimidad como definidores del espacio público. No lo hacen como actores influyentes en el mercado capitalista naciente sino como interventores en el espacio político.

Al tomar conciencia de las posibilidades discursivas que les abre la figura del indio, los indigenistas cuzqueños dan un paso adelante redefiniendo lo que se podría llamar la herencia patrimonial andina. Se trataba de una producción discursiva en que los elementos constitutivos pertenecían al universo de la representación. La cronística de los siglos XVI y XVII era el lugar patrimonial obligatorio para la construcción del discurso. Lo es también la práctica arqueológica que se expande por esas décadas donde emergía la figura impar de Julio C. Tello, iluminada por la voluntad de dar a los tiestos una dimensión política de corte netamente nacionalista. Resumo: se aunan dos fuerzas en el indigenismo, la primera introducía al indio en el discurso societal, la segunda producía un discurso patrimonial con muros, edificios y objetos desenterrados por la práctica arqueológica.

\footnotetext{
21 lbidem.

${ }^{22}$ El tema de la postmodernidad y sus relaciones con el turismo han sido tema frecuente de estudio: George Ritzer and Allan Liska,

"McDisneyization and Post-Tourism", Touring Cultures. Transformation of Travel and Theory, Chris Rojek and John Urry, eds. Routledge, London, 1997: 96-109.

23John Urry, The Tourist Gaze, Sage, London, 1990; del mismo autor, Consuming Places, Routledge, London, 1995. VV.AA., op.cit., London, 1997.

${ }^{24} \mathrm{La}$ emplea con asegurado éxito las muy recientes investigaciones sobre la experiencia turística peruana llevadas a cabo por Alexandra Arellano, de la Universidad de Lancaster ( Reino Unido), con el apoyo tutorial de John Urry.
}

\section{IV.- Patrimonio y postmodernidad: la mirada turística 22}

\section{La mirada turística23}

Para no quedarme con el tema del indigenismo, que para algunos puede parecer usado y sobado, me referiré a un novedoso enfoque en el que por la primera vez se ponen en evidencia algunas de las dimensiones más espectaculares de la cultura contemporánea: la mirada turística. La expresión fue acuñada por John Urry en el título de un libro24. El intento para comprender cómo se va produciendo el discurso sobre la práctica turística echará alguna luz sobre las características que definen el entorno peruano de la práctica turística 25 . Veamos qué hipótesis de lectura nos puede ofrecer ese novedoso enfoque.

No cabe la menor duda de que la experiencia turística es la consecuencia de una revolución en las costumbres de las sociedades contemporáneas, las cuales por razones muy variadas van ampliando sus fronteras y digiriendo lo que las distintas culturas van ofreciendo como productos de consumo. La gran novedad reside precisamente en ese hecho tan anodino como ambiguo: ofrecer a la mirada de un anónimo viajero un conjunto de paisajes, objetos y personas. Por definición la mirada es rápida y breve la estadía. El turista tiene el tiempo apretado. Llega para ver, no para quedarse. Hoy está en el Perú, mañana en Nigeria, el próximo año en Bali, con la misma curiosidad y la misma prisa de mirar y con la mirada, consumir. La palabra adecuada: consumir26.

Ahora bien, para consumir hay que producir. ¿En qué condiciones y en qué contexto se produce? ¿Qué variedades de productos se

\footnotetext{
${ }^{25}$ Debo a Alexandra Arellano, la existencia de esta nueva literatura. Como colaboradora en este mismo número de la revista retoma estos temas con enfoque novedoso y original. Sus investigaciones sobre el espacio turístico surandino aportan nueva luz sobre algunas de las dimensiones del fenómeno turístico peruano.

${ }^{26}$ Eeva Jokinen and Soile Veijola, "The Desoriented Tourist. The Figuration of the Tourist in Contemporary Cultural Critique", VV.AA., op. cit., London, 1997: 23-51.
} 
ofrecen? Arellano llama la atención sobre dos dimensiones que se esconden detrás de los ojos del turista: a) la práctica turística como oferta en el mercado y b) la recepción del producto como consumo27. En este caso, las preguntas son: ¿Cómo se va diseñando la producción de un producto que se ofrece en el mercado; ¿Cuál es la reacción del consumidor - turista - frente a él?

\section{El turismo como producto de mercado}

Al asumir que el turismo es un producto que se rige por los mismos principios del mercado, se acepta también que todos los elementos que entran en su definición deben obedecer al principio que sirve de fundamento a la ley de oferta y demanda. En ese caso, el Perú propone al turista los paisajes, los productos elaborados por sus gentes, la herencia que le dejaron sus antepasados.Y todo ello en el contexto de la relación creada por el juego de la oferta/venta y de la demanda. Lo que se presenta a los ojos del turista corresponde a lo que una empresa minera extranjera busca en el subsuelo, hierro, cobre, oro. De la misma manera que el "producto turístico" se proporciona a la demanda consumidor-turista, el producto minero se presenta en el mercado de materias primas. Ojo: en términos de práctica socioeconómica los dos productos son rigurosamente iguales.

Al introducir el producto turístico en la red del mercado y al enfocarlo como objeto de consumo los elementos que lo componen pasan a poseer las mismas características que todos los productos de consumo en las sociedades contemporáneas. El paisaje, los bienes, el patrimonio son vendidos y consumidos, es decir, objeto de una "mirada" que compró el turista en el breve tiempo que disfrutó en verlo. Lo que los ojos miraron corresponde al consumo que satisface al gusto o que reconforta el cuerpo con un instante de placer. A la multiplicidad de sensaciones y a la variedad de experiencias se podría llamar el enfoque postmodernista de la

${ }^{27}$ Alexandra Arellano, Mirada postmoderna y turismo surandino. Ms., University of Lancaster, 1999. cultura. Exploraré esta veta siguiendo sugerencias de los trabajos de Arellano.

\section{La mirada turística y la conciencia fragmentada}

La conciencia postmoderna se caracteriza por la fragmentación de los valores y normas que rigen las prácticas sociales y la conducta de los grupos y clases ${ }^{28}$. La ausencia de una visión del mundo que se impone a los individuos y grupos en forma de totalidad, da lugar a la construcción fragmentada del universo de valores y normas. Por consiguiente, el individuo se dota de su propio código de conducta y rechaza o ignora lo que el grupo le ofrece como universo total de normas y valores. Elige lo que más le conviene en las circunstancias que el tiempo y el espacio de momento le señalan. En cada caso, la opción por una o por otra conducta no obedece a ningún principio totalizante y depende, por regla general, de la experiencia pasajera y de la sensación efímera que habita el individuo.

Empleé la palabra "efímero". También se podría usar la de volátil. Lo señalaron varios autores y lo tomaron como la principal característica de las prácticas de las actuales sociedades. No cabe duda que las dos expresan los ejes en torno de los cuales se teje la práctica social contemporánea y la definen como conciencia fragmentada. Con ella también se afirma el carácter universal de la oferta y la demanda, el cual pone a la disposición y al alcance del individuo todo lo que las sociedades producen o definen, verbi gratia, espacios físicos, usos y costumbres, herencias y bienes simbólicos. En otras palabras, el peso que cada cosa tiene es producto del mercado, es decir, del juego de la oferta y de la demanda.

\footnotetext{
${ }^{28}$ Jürgen Habermas, Der philosophische Diskurs der Moderne. Zwölf Vorlesungen, Frankfurt -zur-Main, 1985 Anthony Giddens, Capitalismo y la moderna teoría social. Un análisis de los escritos de Marx, Durkheim y Max Weber, IDEA Books, Barcelona, 1998; VV. AA., Las consecuencias perversas de la modernidad, Josetxo Beriain, comp., Anthropos, Barcelona, 1996.
} 


\section{Patrimonio versus conciencia fragmentada}

De lo expuesto se concluye fácilmente que el campo definido por el vocablo "patrimonio" rehuye a todas las manifestaciones de la conciencia fragmentada. Como queda señalado más arriba, la idea misma de "patrimonio" subraya la continuidad y herencia, mientras la de conciencia fragmentada apunta hacia el vacío del contenido simbólico y a la ahistoricidad del objeto. Corresponde éste a lo efímero y volátil de la mirada turística, aquél al esfuerzo estamentario, grupal o clasista desplegado en la producción del discurso que ata la comunidad o el grupo a sus raíces históricas o simbólicas. En ese sentido, la conciencia fragmentada del individuo contemporáneo pone entre paréntesis la continuidad histórica y el turista se ahorra el discurso de la herencia patrimonial. Por definición, el turista consume en el instante mismo lo que le ofrecen los productores de bienes y servicios. Estos son los que definen, en última instancia, el destino del patrimonio 29 .

No se entiende la mirada turística sin la existencia del mercado. Sin el juego de la oferta y de la demanda sería incomprensible la exposición del patrimonio al turista. Como objeto de oferta y demanda, el patrimonio pierde su condición de herencia identitaria para tornarse un capital cuyo valor depende de la capacidad de promoción y de intervención en los puntos de venta, es decir grandes agencias de turismo, cadenas hoteleras, compañías de aviación. El patrimonio pasa a ser un objeto ad extra y no ad intra, objeto que se adecua a la "mirada turística" y no a la expresión de un proyecto colectivo tanto regional como nacional. El valor será determinado por la colocación del producto en el mercado y no por la conciencia de asumir una herencia. De igual manera, dependerá de las reglas de juego del mercado, la contribución del

\footnotetext{
${ }^{29}$ Hasta cierto punto, la idea de Tradición plantea los mismos problemas en el contexto de las sociedades contemporáneas. Sobre el tema, Henrique Urbano, comp. , Tradición y modernidad en los Andes (Estudios y debates regionales andinos, 86), CBC, Cuzco, 1997.
}

patrimonio a la hipotética definición de un proyecto colectivo apuntando hacia el futuro. Ahora bien. ¿Cómo enfocar esa tirantez entre el patrimonio y la conciencia fragmentada producida por las sociedades contemporáneas y las prácticas sociales del mercado? ¿Cómo ubicar correctamente la herencia identitaria del entorno patrimonial y los obstáculos que la mirada turística y lo que la genera producen?

\section{V.- Experiencias patrimoniales fragmentadas}

\section{La experiencia del Estado y la memoria de la Nación}

Siguiendo los pasos de Pierre Nora se podría afirmar que la toma de conciencia de la existencia de la memoria pasó por varias etapas, siendo la que siguió a la gesta de la Independencia, la que forjó el discurso del Estado sobre la herencia colectiva de la nación peruana ${ }^{30}$. Arellano duda que sea una idea original31. Según ella, muchas sociedades occidentales siguieron ese modelo que echó raíces en los primeros ensayos de la Revolución francesa y que se afirmó durante todo el siglo XIX. La conciencia patrimonial estaba al servicio del Estado, que disponía libremente de ella. Ahora bien, el fin de la presencia del Estado en la sociedad, la conciencia de que el Estado-Providencia ha llegado a su fin, planteó de nuevo el papel que desempeña el patrimonio en la producción de una historia identitaria común. La apertura democrática de la sociedad peruana terminó por dar la razón a los que echaban mano de nuevas vetas en sus esfuerzos para desprender la memoria de la Nación de las garras del Estado. Sin ser un éxito absoluto, y sin una clara línea demarcatoria entre la herencia estatal y la memoria común, hay indicios que señalan la existencia de una conciencia nueva, aunque en un contexto

\footnotetext{
30Pierre Nora, "La nation-mémoire", Pierre Nora, comp., Les lieux de mémoire, 2, Quarto, Gallimard, Paris, 1997: 2207-2216.

${ }^{31}$ Alexandra Arellano, op. cit., ms. 1999: 56.
} 
en que la práctica estatal sigue muy presente. Ya lo veré más adelante. Por ahora señalo lo que indica Arellano.

Ocurrió lo que parece ser una tendencia general de la sociedad contemporánea, agudizada en los últimos años por el derrumbe de las sociedades socialistas. Recuérdese que éstas estaban totalmente sometidas al régimen estatal, donde la memoria era la propia invención del aparato político del Estado. En esas condiciones, se confundían y entremezclaban la herencia de la Nación con el partido político, en el juego de intereses burocráticos que el Estado necesitaba para difundirse y para controlar despiadadamente la conciencia patrimonial de la Nación. No había Nación fuera del Estado, ni conciencia común sin el discurso autorizado por él. El patrimonio era un elemento más en la cadena de argumentos de que sacaba provecho el poder estatal para justificar su prepotencia y arbitrariedad.

Las aperturas democráticas y los espacios públicos a que he hecho referencia anteriormente terminaron mermando los tentáculos del Estado y aflojando sus riendas. En esa ola se van lanzando los grupos, clases y hasta individuos en búsca de una herencia que les había sido ñnegada por la fuerza arbitraria del poder político estatal. Y la Nación deja de ser un objeto exclusivo del Estado para tornarse la herencia común.

\section{Patrimonio y búsqueda identitaria}

Al desertar el Estado, la conciencia de pertenecer a un grupo o clase con un pasado común y con objetivos definidos agudizó el interés por lo que se podría llamar la búsqueda identitaria. $Y$ hasta el individuo se impregnó de esa misma mística. Abandonado a sí mismo trató de sacar de su propia "historia" los recursos patrimoniales que le dejaron las vivencias personales y el recuerdo. Por consiguiente, tanto a nivel de los grupos o clases como a nivel de los individuos, el patrimonio designa en las sociedades contemporáneas el campo de producción continua de un discurso sobre los rasgos o elementos de una herencia común. Son los propios grupos o clases y los individuos que lo definen ya no de una manera definitiva y estática, sino en el juego de intereses a que todos echan mano según las circunstancias de tiempo y lugar.

En ese sentido, la propia experiencia del mercado a que hemos hecho referencia se adecua mejor a la conciencia patrimonial de las sociedades actuales. Es obvio, concederá el lector. Al producir un discurso para el turista y al ofrecer a su mirada, que no se fija detenidamente sobre un objeto sino que se dispersa en múltiples blancos, los elementos constitutivos de una memoria común o la palabra individual de una vivencia, la conciencia patrimonial se vuelve tan efímera como lo es la demanda del propio turista. Pese a la energía que ella despliega para retener el tiempo y fijarse en un espacio, no perderá su condición presente que es la de dar a su propio patrimonio las condiciones que lo transforman en un elemento más de la volatilidad de las sociedades contemporáneas. Aunque sea una época en que la producción del discurso patrimonial estaba en ciernes, la clase empresarial cuzqueña elige la Semana turística en 1944 y escenifica el Inti Raymi para los ojos del visitante ${ }^{32}$. Lo que importa en la producción del ritual es entregar a la mirada turística un objeto en que ella pueda momentáneamente deleitar y descansar sus ojos. De igual manera, se multiplican los sitios arqueológicos para que puedan verlos y consumirlos los ojos del turista. Si a éstos no les interesa la búsqueda de una identidad, a la clase empresiarial cuzqueña le interesa vender. El Inti Raymi no es una creación patrimonial, es un objeto en una vitrina para la mirada del turista.

${ }^{32}$ Alexandra Arellano, op. cit., ms. 1999: 37. 


\section{VI.- Conclusión}

Estas breves y algo desaliñadas reflexiones pretenden ubicar el debate en torno al patrimonio en el contexto de la experiencia de vida de las sociedades contemporáneas. Insistí en el hecho de que el advenimiento y difusión del pensamiento crítico, fundamento de la modernidad en su estricto sentido, cambió radicalmente nuestra concepción del patrimonio y la definición de nuestra herencia común. Asimismo, la difusión universal de la práctica económica del mercado invadió todos los campos de la actividad humana y la conciencia patrimonial no escapa a sus redes. Se podrá llamar a lo efímero de esas prácticas sociales presentes conductas postmodernas. Pero cualquiera que sea el nombre o la expresión empleada, es siempre la fragmentación de la conciencia patrimonial la que se subraya y con ella el fin de la herencia identitaria como un objeto fijo e inamovible.

Henrique Urbano

Director del Instituto de Investigación

Facultad Turismo

Universidad San Martín de Porres

Lima, Perú

Ogil@fccsmp.edu.pe 